\title{
Clinical outcomes of previously untreated patients with unresectable intrahepatic cholangiocarcinoma following proton beam therapy
}

Shosei Shimizu ${ }^{1 *}$, Toshiyuki Okumura ${ }^{1}$, Yoshiko Oshiro ${ }^{1}$, Nobuyoshi Fukumitsu' ${ }^{1}, K_{\text {Kuniaki Fukuda }}^{2}$, Kazunori Ishige ${ }^{2}$, Naoyuki Hasegawa ${ }^{2}$, Haruko Numajiri ${ }^{1}$, Keiko Murofushi ${ }^{1}$, Kayoko Ohnishi ${ }^{1}$, Masashi Mizumoto ${ }^{1}$, Tetsuo Nonaka', Hitoshi Ishikawa ${ }^{1}$ and Hideyuki Sakurai ${ }^{1}$

\begin{abstract}
Background: The effectiveness of proton beam therapy (PBT) as initial treatment for patients with unresectable intrahepatic cholangiocarcinoma (ICC) is unclear, particularly as related to ICC histological subtypes. We performed this study to address this gap in knowledge.

Methods: Thirty-seven patients with unresectable ICC who underwent PBT as their initial treatment were evaluated. Twenty-seven patients had Child-Pugh class A liver function, 11 exhibited jaundice, and 10 had multiple tumors. Nineteen, 7, and 11 tumors were classified as mass forming (MF), periductal infiltrating (PI), and intraductal growth (IG) types, respectively, based on gross appearance in imaging studies. Patients were classified into the curative group $(n=25)$ and palliative group $(n=12)$ depending on whether the planning target volume covered all the macroscopic tumors.
\end{abstract}

Results: The 1- and 2-year overall survival rates were 60.3 , and $41.4 \%$, respectively; the median survival time (MST) was 15 months for all patients. The MSTs for curative and palliative groups were 25 and 7 months, respectively. Curative treatment and adjuvant chemotherapy significantly improved overall survival, while the presence of periductal infiltrating type tumors was a negative prognostic factor. In the curative group, the 1- and 2-year local control rates were 100 and $71.5 \%$, respectively, while the 1-, and 2-year progression-free survival rates were 58.5, and $37.6 \%$, respectively. No severe acute toxicities were observed. Three patients experienced grade 3 biliary tract infection, although it was unclear whether this was radiotherapy-related.

Conclusion: PBT may yield to improve survival and local tumor control among patients with unresectable ICC. Keywords: Intrahepatic cholangiocarcinoma, Proton beam therapy, Survival, Macroscopic type, Unresectable ICC

\section{Precis}

Proton beam therapy as the initial treatment significantly improves survival in patients with intrahepatic cholangiocarcinoma, and has a good safety profile. This is especially true when administered as curative treatment in combination with chemotherapy.

\footnotetext{
* Correspondence: 23s.showsay.shimizu@gmail.com

1 Department of Radiation Oncology and Proton Medical Research Center, Faculty of Medicine, University of Tsukuba, 1-1-1, Tennodai, Tsukuba, Ibaraki 305-8575, Japan

Full list of author information is available at the end of the article
}

\section{Introduction}

Intrahepatic cholangiocarcinoma (ICC) is the second most common primary liver cancer by hepatocellular carcinoma and accounts for $10 \%$ of primary liver malignancies. Although surgery is considered the only curative treatment for ICC, only $30 \%$ of such tumors are resectable at the time of diagnosis. The standard treatment for unresectable ICCs is chemotherapy; however, the median survival time (MST) for such patients is dismal [1]. Until recently, radiotherapy was indicated for intrahepatic malignancies only as a palliative treatment;

(C) The Author(s). 2019 Open Access This article is distributed under the terms of the Creative Commons Attribution 4.0 International License (http://creativecommons.org/licenses/by/4.0/), which permits unrestricted use, distribution, and 
however, recent technological advances have allowed for the use of radiotherapy as curative-intent treatment, with favorable results even observed in patients with ICC $[2,3]$. In particular, proton beams can achieve excellent dose localization, and we previously reported favorable outcomes in patients who underwent proton beam therapy (PBT) for hepatic tumors including hepatocellular carcinoma (HCC) [4-6], metastatic liver tumors $[7,8]$, and ICC (including in 20 patients treated between 1995 and 2009) [2].

The gross appearance of ICC is classified into 3 subtypes according to the Liver Cancer Study Group of Japan [9]; the mass forming (MF), periductal infiltrating (PI), and intraductal growth (IG) types. These 3 tumor subtypes have different biological behaviors and are associated with different prognoses after surgical resection. It is generally considered that lymph node metastasis is less frequent in IG-type ICCs [10-12], while perineural invasion is high in MF and PI types [10]. However, the influence of the macroscopic type on the results of radiotherapy has not been previously described. In this study, we analyzed the outcomes of patients who underwent PBT as an initial treatment for unresectable ICC.

\section{Methods}

\section{Patients}

Forty-two patients with ICC were administered PBT as their initial treatment at our current facility between 2001 and 2017. Five of these patients had resectable disease but refused to undergo surgery; of remaining 37 patients, 5, 22 , and 10 had unresectable tumors owing to their medical condition (old age or poor performance status [PS]), tumor progression, and both, respectively. The latter 37 patients were investigated in our study. The patients' characteristics are shown in Table 1; they included 22 men and 15 women with a median age of 68.4 years (range: 32-87 years). The Eastern Cooperative Oncology Group PS scores were 0,1 , and 2 for 12, 19, and 6 patients, respectively. In terms of liver function, 27 and 10 patients were classified as Child-Pugh A and B, respectively. Eleven patients were jaundiced at presentation; 4, 4, 19, and 10 were diagnosed with stage I, II, IVA, and IVB disease, respectively, acording to the TNM classification (UICC version 7). Twenty patients had ICC confirmed via histology while the remainder were diagnosed based on imaging study including dynamic contrast-enhancement CT scans and MRI, positive tumor markers of carcinoembryonic antigen (CEA) or carbohydrate antigen 19-9 (CA19-9) with negative $\mathrm{HCC}$-specific tumor markers such as alphafetoprotein (AFP) and protein induced by vitamin $\mathrm{K}$ absence or antagonist-II (PIVKA-II). The tumor diameters ranged from 15 to $140 \mathrm{~mm}$ with a median of $57 \mathrm{~mm}$. Twenty-seven patients had a solitary tumor and 10 patients had multiple tumors. The tumors in 19, 7, and 11 patients were classified as MF, PI, and IG types, respectively, based on CT findings. 25 and 12 patients received PBT with curative and palliative intent, respectively, depending on whether the planning target volume covered all detected macroscopic tumors including positive lymph nodes (curative) or not (palliative). Five patients of the 10 with multiple tumors received PBT in curative intent but other 5 patients had multiple tumor located at both lobe and lymph node or distant metastases, and they received PBT in palliative intent in order to avoid bile duct stenosis at hepatic portal region. In the curative group that comprised 25 patients, the tumors of 13,4 , and 8 were classified as MF, PI and IG types, respectively.

\section{PBT administration}

For treatment planning, fiducial markers were implanted into the normal liver tissue close to the tumor boundary for patient positioning. The patient's body was immobilized using an individually shaped body cast (ESFORM; Engineering System Co., Matsumoto). CT using $5 \mathrm{~mm}$ thick slices was then performed in the treatment position during the end-expiratory phase with the support of a respiratory-gaiting system. The clinical target volume for the primary lesion was delineated to encompass the gross tumor with $5-10 \mathrm{~mm}$ margins in 3 dimensions, and caudal $5 \mathrm{~mm}$ margins were added to compensate for any potential hepatic movement. The clinical target volume for nodal lesion was drawn to cover the clinically positive nodes with $5 \mathrm{~mm}$ margins if required. Elective nodal irradiation was not performed. Next, $5-10 \mathrm{~mm}$ margins were added to define the planning target volume. Treatment beams were delivered via the double scattering mode during the end of the expiratory phase using a respiratory gating system as described previously [13].

The median prescribed dose was $72.6 \mathrm{GyE}$ in 22 fractions; the doses ranged from $46.6 \mathrm{GyE}$ in 12 fractions to $74.0 \mathrm{GyE}$ in 37 fractions. Basically, the dose prescription for curative-intent therapy was dependent on tumor location, and was $72.6 \mathrm{GyE}$ in 22 fractions (biological effective dose $(\alpha / \beta=10)$ [BED]: $96.6 \mathrm{~Gy})$ for porta hepatis, 74GyE in 37 fractions (BED: 88.8 Gy) for $2 \mathrm{~cm}$ from gastrointestinal tract, and $66 \mathrm{GyE}$ in 10 fractions (BED:109.6 Gy) for tumor not adjacent to gastrointestinal tract and porta hepatis. The relative biological effectiveness of the proton beam was designated as 1.1 [14]. The tumor was covered by $>$ $95 \%$ of the prescribed dose at the isocenter, however, the target volume was usually modified according to dose constraints for the gastrointestinal tract so as not to exceed a maximum dose of $50 \mathrm{~Gy}$. Also, the percentage volumes of normal liver receiving at least $0,10,20$, and $30 \mathrm{GyE}(\mathrm{V} 0,10,20$, and 30 ) of 30, 20, 26 , and $18 \%$ were used as an adequate indication [15]. One, 21, and 5 patients received $66.0 \mathrm{~Gy}$ in 10 
Table 1 Patient Characteristics $(n=37)$

\begin{tabular}{|c|c|c|c|}
\hline & & Curative group $(n=25)$ & Palliative group $(n=12)$ \\
\hline Median Age (range) & $68.4(32-87)$ & $72(44-82)$ & $67(32-87)$ \\
\hline \multicolumn{4}{|l|}{ Gender } \\
\hline Male & 22 & 17 & 5 \\
\hline Female & 15 & 8 & 7 \\
\hline \multicolumn{4}{|l|}{ Performance status } \\
\hline 0 & 12 & 11 & 1 \\
\hline 1 & 19 & 13 & 6 \\
\hline 2 & 6 & 1 & 5 \\
\hline 3 & 0 & 0 & 0 \\
\hline \multicolumn{4}{|l|}{ Child-Pugh Classification } \\
\hline$A$ & 27 & 20 & 7 \\
\hline B & 27 & 5 & 5 \\
\hline \multicolumn{4}{|l|}{ Jaundice } \\
\hline yes & 26 & 21 & 5 \\
\hline no & 11 & 4 & 7 \\
\hline \multicolumn{4}{|l|}{ Treatment intent } \\
\hline Curative & 25 & & \\
\hline Palliative & 12 & & \\
\hline Median size of the tumor (range) (mm) & $57(15-140)$ & $44(15-140)$ & $60(22-110)$ \\
\hline \multicolumn{4}{|l|}{ Number of tumor } \\
\hline single & 27 & 22 & 5 \\
\hline multiple & 10 & 3 & 7 \\
\hline \multicolumn{4}{|l|}{ TNM stage (7th UICC) } \\
\hline I & 4 & 4 & 0 \\
\hline$\|$ & 4 & 3 & 1 \\
\hline III & 0 & 0 & 0 \\
\hline IVa & 19 & 15 & 4 \\
\hline $\mathrm{IVb}$ & 10 & 3 & 7 \\
\hline \multicolumn{4}{|l|}{ T stage } \\
\hline 1 & 5 & 5 & 0 \\
\hline $2 a$ & 6 & 4 & 2 \\
\hline $2 b$ & 5 & 1 & 4 \\
\hline 3 & 1 & 1 & 0 \\
\hline 4 & 20 & 14 & 6 \\
\hline \multicolumn{4}{|l|}{$N$ stage } \\
\hline 0 & 21 & 17 & 4 \\
\hline 1 & 16 & 8 & 8 \\
\hline \multicolumn{4}{|l|}{ M stage } \\
\hline 0 & 27 & 22 & 5 \\
\hline 1 & 10 & 3 & 7 \\
\hline \multicolumn{4}{|l|}{ macroscopic subtype } \\
\hline Mass forming (MF) type & 19 & 13 & 6 \\
\hline Intraductal growth (IG) type & 7 & 4 & 3 \\
\hline Periductal infiltrating (PI) type & 11 & 8 & 3 \\
\hline
\end{tabular}


Table 1 Patient Characteristics $(n=37)$ (Continued)

\begin{tabular}{|c|c|c|c|}
\hline & & Curative group $(n=25)$ & Palliative group $(n=12)$ \\
\hline \multicolumn{4}{|l|}{ Total dose } \\
\hline 66.0 GyE in 10 Fraction (BED*:109.6 Gy) & 1 & 1 & 0 \\
\hline 72.6 GyE in 22 Fraction (BED:96.6 Gy) & 21 & 19 & 2 \\
\hline 74.0 GyE in 37 Fraction (BED:88.8 Gy) & 5 & 2 & 3 \\
\hline Other (BED < 88.8Gy) & 10 & 3 & 7 \\
\hline \multicolumn{4}{|l|}{ Concurrent chemotherapy } \\
\hline TS-1 & 15 & 11 & 4 \\
\hline Gemcitabine & 1 & 1 & 0 \\
\hline None & 21 & 13 & 8 \\
\hline \multicolumn{4}{|l|}{ Adjuvant Chemotherapy } \\
\hline TS-1 & 10 & 7 & 3 \\
\hline Cisplatine + Gemcitabine & 5 & 4 & 1 \\
\hline Gemcitabine & 4 & 2 & 2 \\
\hline None & 18 & 11 & 7 \\
\hline
\end{tabular}

"BED: biological effective dose $(\alpha / \beta=10)$

fractions, $72.6 \mathrm{~Gy}$ in 22 fractions, and $74.0 \mathrm{~Gy}$ in 37 fractions, respectively. 10 patients received less than an BED of $88.8 \mathrm{GyE}$ (equivalent to $74 \mathrm{~Gy}$ in 37 fractions): $70.0 \mathrm{~Gy}$ in 35 fractions, $66.0 \mathrm{~Gy}$ in 20 fractions, 66.0Gy in 30 fractions, $59.4 \mathrm{~Gy}$ in 18 fractions, 55.0 Gy in 10 fractions, and 46.6 Gy in 12 fractions for 1 , $2,1,1,2$, and 1 patients, respectively (Table 1 ).

\section{Chemotherapy}

Sixteen patients received concurrent chemotherapy to achieve a radiosensitizing effect, 15 of whom received oral chemotherapy with tegafur, gimeracil, and oteracil (TS-1), while the remaining patient received intravenous gemcitabine. Maintenance chemotherapy was administered after PBT to 19 patients, 10 of whom received TS1 and 9 received intravenous chemotherapy (cisplatin plus gemcitabine: 5 , gemcitabine alone: 4 ).

\section{Analysis}

The overall survival rate was calculated from the date of PBT commencement to that of death or March 2018. Local failure was defined as an increase of at least 20\% in the sum of the target lesion diameters by diagnostic imaging such as CT and MRI. Progression was defined as local recurrence or the appearance of new legions. Toxicities were graded according to National Cancer Institution Common Terminology Criteria for Adverse Events version 4.0 [16].

Survival and local control rates were calculated using the Kaplan-Meier method, and differences between 2 groups were determined using the log-rank test. Factors that significantly influenced survival and local control were identified using the Cox proportional hazards model. A $P$-value of $<0.05$ was considered significant.

\section{Results}

Survival

Among the 37 patients, 10 were alive at the last follow-up date, 25 had died from cancer progression, and 2 had died from reasons other than ICC. The median follow-up time was 37.5 months, and the MST was 15.0 months with cumulative 1- and 2- years survival rates of $60.3 \%$ (95\% confidence interval [CI]: 44.7-76.6\%), and $41.4 \%$ (95\% CI: $24.5-58.3 \%$ ), respectively, for all patients (Fig. 1a). There was a significant difference in survival between the curative and palliative group $(P=0.001)$ (Fig. 1b). In the curative group, the MST was 25 months with 1- and 2-year overall survival rates of $66.3 \%$ (95\% CI: $47.3-85.3 \%$ ), and 52.4\% (95\% CI: 31.8-73.0\%), respectively. For patients in the palliative group, the MST was 7 months with 1-, and 2-year overall survival rates of $27.5 \%$ (95\% CI: 1 $54 \%$ ), and $18.3 \%$ (95\% CI: $0-41.2 \%$ ), respectively. Other factors that were associated with significantly improved survival were Child-Pugh A liver function $(P=0.004)$, absence of jaundice $(P=0.002)$, and undergoing maintenance chemotherapy $(P=0.000)$. The MST for patients treated with or without maintenance chemotherapy were 49 months and 10 months, respectively (Table 2).

Although the macroscopic tumor type was not a significant survival factor among all patients combined, it was a significant factor specifically in the curative group, in which survival was significantly worse for patients with PI-type tumors than for those with the other 2 tumor types (PI vs. MF: $P=0.022$; PI vs. IG: $P=$ 0.023 ; MF vs. IG: $P=0.784$ ), and the median survival times were 61 months, 31 months, and 9.0 months for patients with IG-, MF-, and PI-type tumors (Fig. 1c). In 


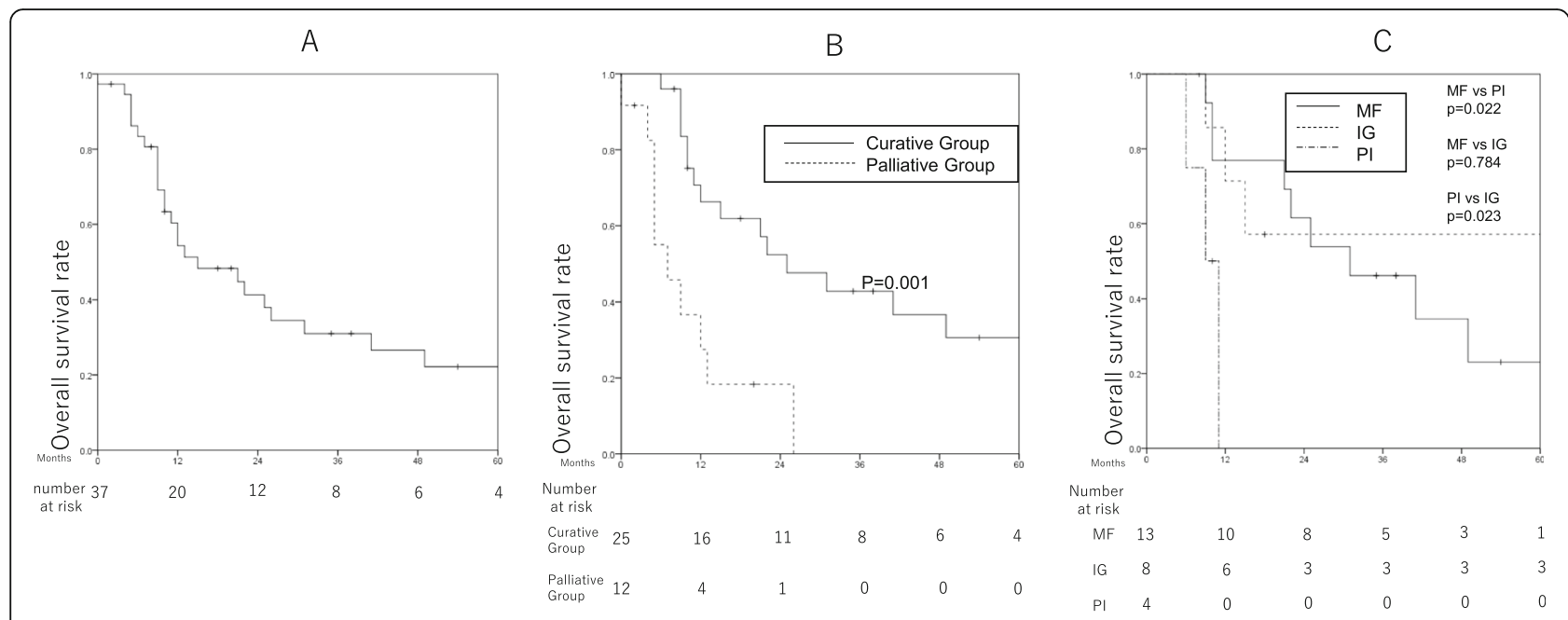

Fig. 1 Kaplan-Meier curves showing the overall survival of patients who underwent proton beam therapy as primary treatment for intrahepatic cholangiocarcinoma. a Overall survival among all patients. b Comparison of overall survival between the curative and palliative groups. (C) Comparison of overall survival among curative-group patients with tumors categorized according to the three macroscopic subtypes. MF: mass forming type, IG: intraductal growth type, Pl: periductal infiltrating type

the curative group, Child-Pugh classification $(P=$ 0.023), jaundice $(P=0.005)$, lymph node metastasis $(P=0.032)$, and maintenance chemotherapy $(P=0.000)$ were also significantly associated with survival.

\section{Disease progression}

The median progression-free survival (PFS) time was 10 months, with 1-, 2-, and 3- years PFS rates of 40.5\% (95\% CI: $24.6-56.4 \%$ ), $26.8 \%$ (95\% CI: $12.5-41.1 \%$ ), and 25.1
(95\% CI: 7.5-34.1\%), respectively, for all patients (Fig. 2a). Eight patients were alive without disease progression on the last follow-up date. In the curative group, the median PFS was 19 months with cumulative 1-, 2-, and 3-year PFS rates of $58.5 \%$ (95\% CI: $38.9-78.1 \%$ ), 37.6\% (95\% CI: $18.2-$ 57.0\%), and 25.1 (95\% CI: 7.6-42.5\%), respectively (Fig. 2b). Six of the 25 patients in the curative group were alive; of the remaining 19 , the manner of initial disease progression was local progression in 3 patients, intrahepatic recurrence

Table 2 Analysis of prognostic factors on overall survival

\begin{tabular}{|c|c|c|c|c|}
\hline \multicolumn{2}{|l|}{ Foctor } & $\begin{array}{l}\text { Patient } \\
\text { number } \\
n=37\end{array}$ & $\begin{array}{l}\text { MST } \\
\text { (months) }\end{array}$ & \multirow{2}{*}{$\begin{array}{l}\text { Univariate analysis } \\
P \text {-value }\end{array}$} \\
\hline \multirow{2}{*}{ Intent } & Curative & 25 & 25 & \\
\hline & Palliative & 12 & 7 & \\
\hline \multirow[t]{2}{*}{ Child-Pugh } & A & 27 & 25 & 0.004 \\
\hline & B & 10 & 9 & \\
\hline \multirow[t]{2}{*}{ Jaundice } & Yes & 11 & 25 & 0.002 \\
\hline & No & 26 & 9 & \\
\hline \multirow[t]{2}{*}{ Lymph node metastases } & Yes & 16 & 15 & 0.344 \\
\hline & No & 21 & 12 & \\
\hline \multirow[t]{2}{*}{ Vessel invasion } & Yes & 32 & 13 & 0.558 \\
\hline & No & 5 & 31 & \\
\hline \multirow[t]{2}{*}{ Tumor number } & multiple & 10 & 9 & 0.272 \\
\hline & single & 27 & 21 & \\
\hline \multirow[t]{2}{*}{ Concurrent chemotherapy } & Yes & 16 & 41 & 0.454 \\
\hline & No & 21 & 13 & \\
\hline \multirow[t]{2}{*}{ Adjuvant chemotherapy } & Yes & 19 & 49 & 0.000 \\
\hline & No & 18 & 10 & \\
\hline
\end{tabular}


A

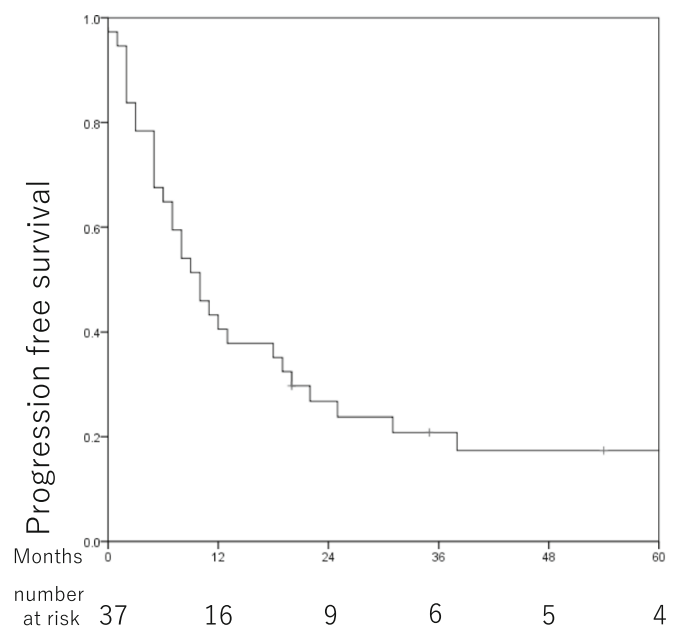

B

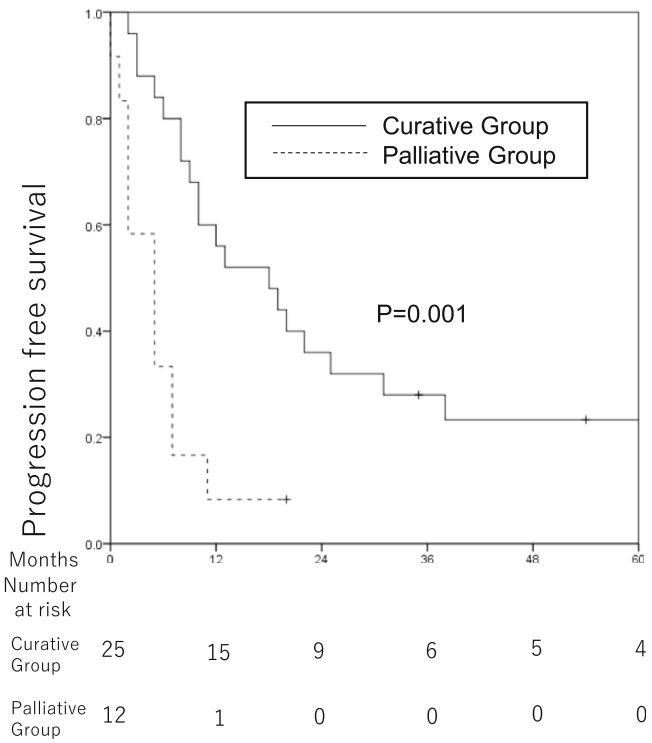

Fig. 2 Kaplan-Meier curves showing the progression-free survival of patients who underwent proton beam therapy as primary treatment for intrahepatic cholangiocarcinoma. a Progression-free survival among all patients. b Comparison of progression-free survival between the curative and palliative groups

outside the treatment field in 9, extrahepatic recurrence in 2 , non-cancer related death in 1, and unknown in 4 .

The change of CA19-9 was shown in Fig. 3. We calculated percentage (\%) of the value prior to PBT. CA19-9 prior to and after PBT was available in 25 patients including 6 patients with palliative intent, and the CA19-9 after PBT decreased in 19 patients of the
25 (76\%). Even with palliative intent, CA19-9 was decreased in 4 of the 6 patients. Of the 25 patients, 15 patients received chemotherapy, but CA19-9 was elevated in 5 patients of the 15. Meanwhile, CA19-9 was elevated only one patient in the 10 who did not received chemotherapy. The median \% of 3-, 6-, 9-, 12-, and 24- months was $61.6 \%$ (9.9-166.0\%), 40.5\% (2.7-

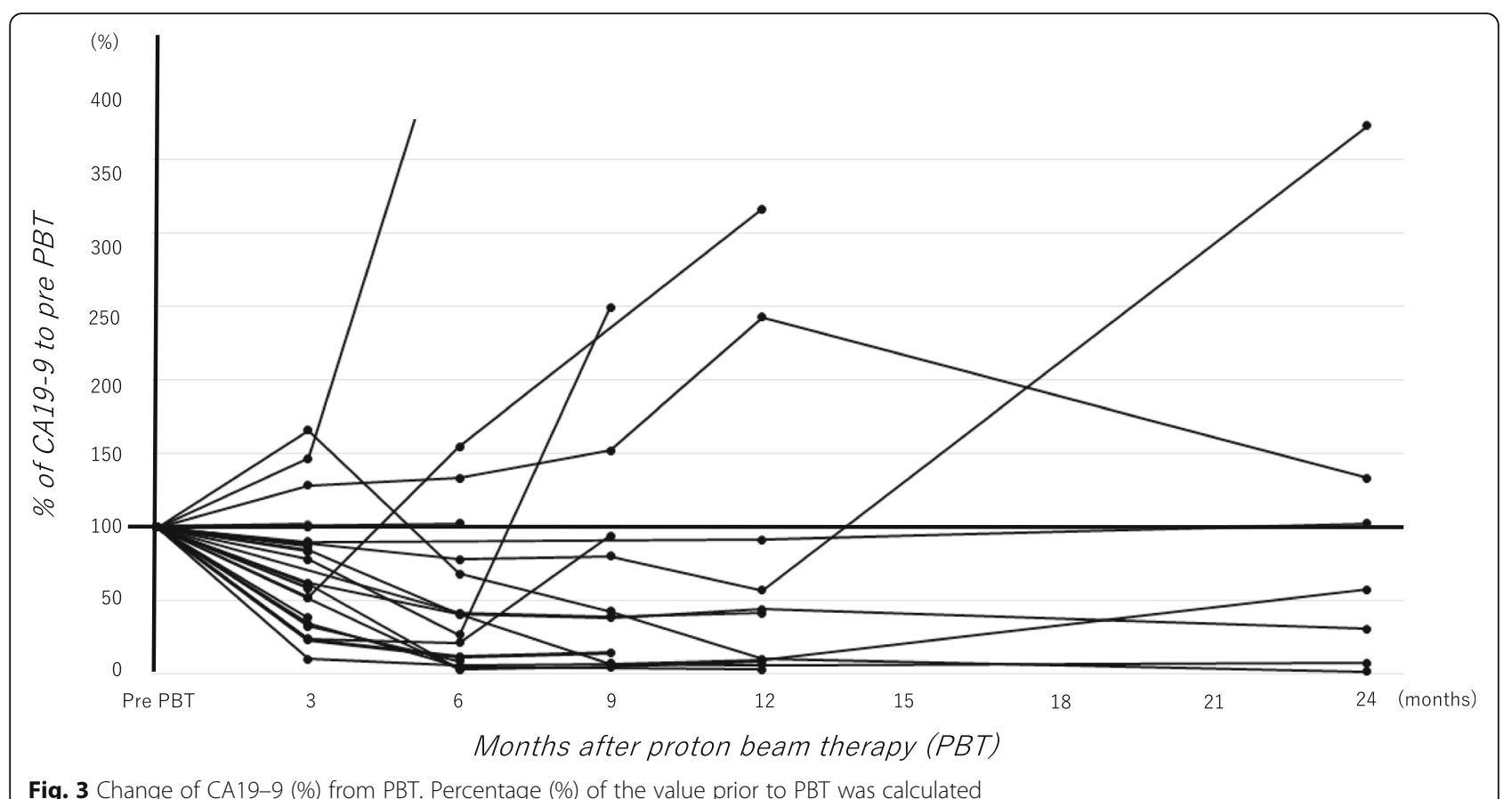

Fig. 3 Change of CA19-9 (\%) from PBT. Percentage (\%) of the value prior to PBT was calculated 
473.9\%), 38.7\% (4.4-250.0\%), 41.5\% (2.8-316.6\%), and $57.4 \%$ (1.8-373.4\%), respectively.

\section{Local control}

Seven patients experienced in-field local failure. The 1- and 2-year local control rates were 97.3\% (95\% CI: 92.0-100\%) and $68.4 \%$ (95\% CI: 46.6-90.2\%), respectively, for all patients; these rates were 100 and $71.5 \%$ (95\% CI: 47.695.4\%), respectively, for curative-group patients (Fig. 4).

Of the 7 patients with in-field local failure, 1 underwent PBT with $46.6 \mathrm{GyE}$ with palliative intent, and the remaining 6 were treated with curative intent. Among patients in the latter group, 1, 3, 1, and 1 received 74 GyE, $72.6 \mathrm{GyE}, 70 \mathrm{GyE}$, and $66 \mathrm{GyE}$, respectively.

\section{Toxicity}

No severe (grade $\geq 3$ ) acute toxicities were observed. In terms of late adverse events, 3 patients experienced grade 3 biliary tract infections (Table 3 ) although it was unclear whether these were linked to PBT; all were managed conservatively with antibiotics.

\section{A case presentation}

A 75-year-old man with a single intrahepatic $70 \mathrm{~mm}$ tumor at the caudate lobe was diagnosed with ICC via liver biopsy. Although he had Child-Pugh A liver function, swollen hepatic portal lymph nodes were detected; therefore, we diagnosed this patient with T1N1M0 stage IVA disease. The tumor was enhanced peripherally on $\mathrm{CT}$ and therefore classified as MF type (Fig. 5a). Surgery
Table 3 Toxicities $(n=37)$

\begin{tabular}{lllll}
\hline Toxicity & Grade 0 / 1 & Grade 2 & Grade 3 & Grade 4 / 5 \\
\hline Acute & 36 & 1 & 0 & 0 \\
$\quad$ Dermatitis & 34 & 3 & 0 & 0 \\
$\quad$ Gastrointestinal ulcer & 34 & & & \\
Late & & 1 & 0 & 0 \\
Gastrointestinal ulcer & 36 & 3 & 3 & 0 \\
Cholangitis & 31 & & & \\
\hline
\end{tabular}

was considered difficult owing to middle- and left-liver vein encasement; therefore, PBT was conducted with $72.6 \mathrm{~Gy}$ in 22 fractions (Fig. 5b). Six months after the PBT, the tumor had shrunk although radiation hepatitis was evident within the beam pathway (Fig. 5c). Three years after undergoing PBT, the tumor had shrunk further and the enhanced legion had disappeared; the lymph node had also shrunk. At the last follow-up visit, this patient was alive with no disease progression 4 years after the PBT (Fig. 5d).

\section{Discussion}

The prognosis of patients with cholangiocarcinoma who receive no treatment is much worse. Park et al. investigated 330 patients with cholangiocarcinoma who did not receive surgery, chemotherapy, or radiotherapy; their median overall survival was 3.9 months; moreover, the median survival time of patients in their cohort with ICC (3 months) was significantly worse than that of patients with hilar cholangiocarcinoma $(5.9$ months, $P<$

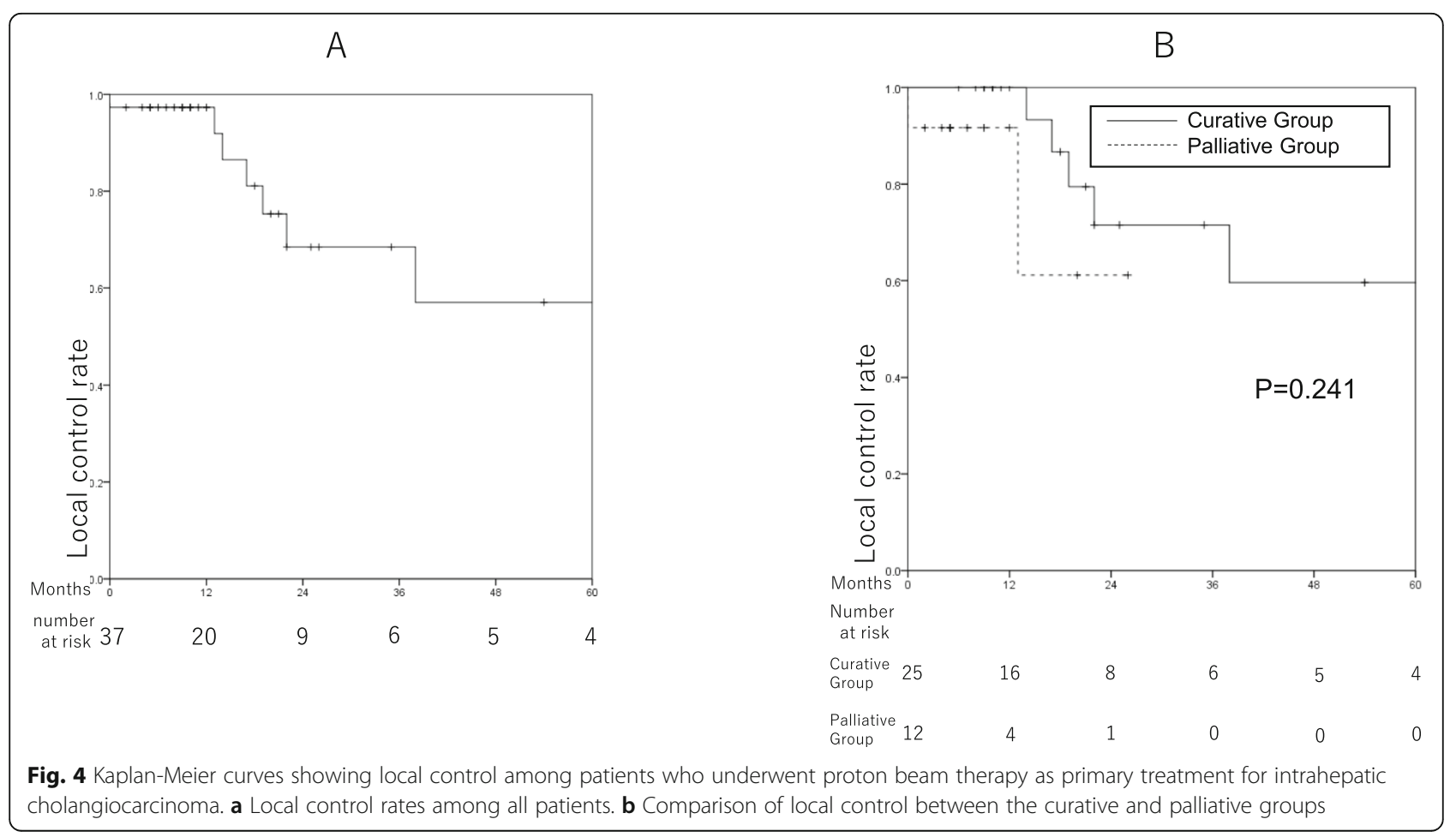


A

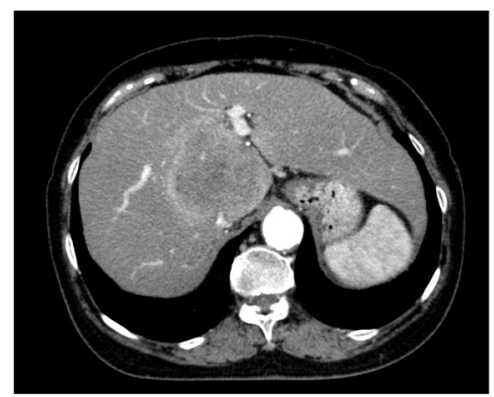

C

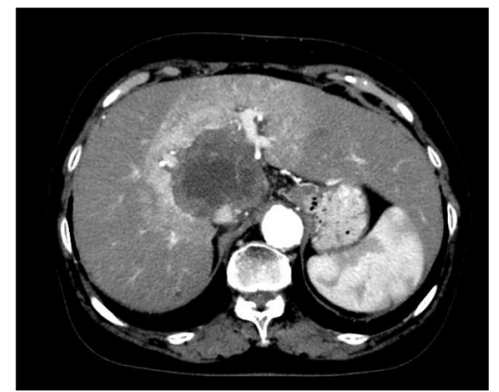

B

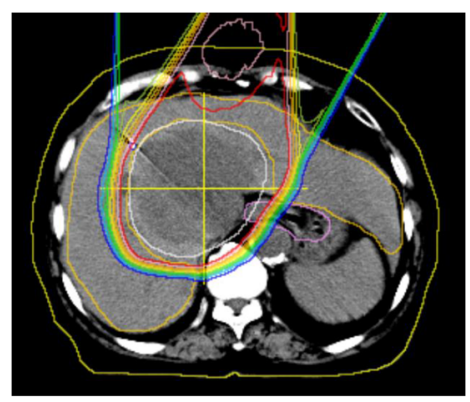

D

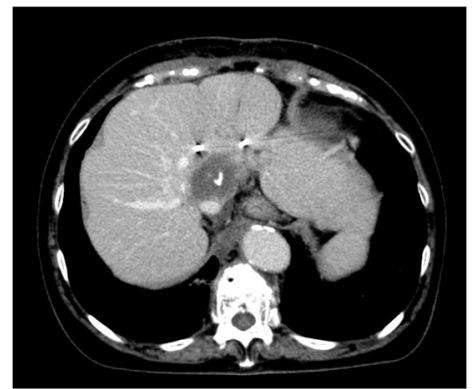

Fig. 5 Imaging features of a 75-year-old man with a single intrahepatic $70 \mathrm{~mm}$ tumor at the caudate lobe who was diagnosed with intrahepatic cholangiocarcinoma. a Computed tomography at diagnosis. b The proton beam therapy dose line. c Six months after proton beam therapy. $\mathbf{d}$ Three years after proton beam therapy

0.001) [17]. Chemotherapy for unresectable ICC has been established. Gemcitabine is a major drug used to treat unresectable biliary duct cancer [18-20], and TS-1 is also used as an alternative [21, 22]. However, treatment outcomes are still extremely poor. A large study by Valle et al. of patients with biliary tract cancer suggested that combination cisplatin plus gemcitabine provided a survival advantage over gemcitabine alone, but the median overall was only 11.7 months [18].

Previously, radiotherapy for ICC was limited to palliative treatment because the liver cannot tolerate extensive irradiation [23]. However, the recent advances in radiotherapy, including stereotactic body radiotherapy (SBRT), intensity modulated radiotherapy, and particle treatment has made possible the delivery of high doses to the tumor while maintaining low doses to normal organs; hence, the indication of radiotherapy for ICC has rapidly expanded [2, 3, 24-26]. SBRT delivers high-dose radiation within a short-term treatment period, and is considered suitable for relatively small tumors (i.e., those less than $5 \mathrm{~cm}$ ). Tse et al. administered SBRT to patients with ICC at the palliative dose of 24 Gy in 6 fractions (biologic equivalent dose $[\mathrm{BED}]=33.6 \mathrm{~Gy})$, and reported an MST of 15 months [24]. Furthermore, Tao et al. recently administered SBRT to 79 patients with unresectable ICC with an escalated dose of $100 \mathrm{~Gy}$ to the center of the tumor, while doses to the gross tumor volume and planning target volume were $75 \mathrm{~Gy}$ and $45 \mathrm{~Gy}$, respectively [25]. The MST was 33 months with a 3-year overall survival rate of $44 \%$, and they suggested that a high BED (greater than $80.5 \mathrm{~Gy}$ ) was significantly correlated with better local control and overall survival. ${ }^{20}$

PBT is also useful for intrahepatic tumors because proton beam dose localization can achieve a homogenous dose distribution with simple beam arrangements (such as with 2 or 3 beams). PBT is reportedly suitable as a higher-dose radiotherapy modality for large liver tumors [27]. Makita et al. suggested clinical outcomes and toxicity of PBT for 28 patients with advanced cholangiocarcinoma including 6 patients with ICC. They suggested overall survival, progression survival and local control rate at 1 year was 49.0, 29.5, and $67.7 \%$, respectively, and that better local control was achieved with BED > 70 Gy [28]. Recently, Hong et al. conducted a phase II study of 37 patients with unresectable ICC who were administered 67.5 Gy in 15 fractions (BED: 97.9 Gy), and reported 2-year local control and overall survival rates of 94.1 and $46.5 \%$, respectively [3]. In our current study, the BED of the treatment dose was greater than 96.6 Gy for the curative group, and the 2-year local control and overall survival rates were 71.5 and $52.4 \%$, respectively. Local recurrence was observed in 4 of the 25 patients in the curative group, and all recurrences were marginal to the target region adjacent to the alimentary tract (where full doses were not delivered for safety considerations). Also, decline of CA19-9 at 3 months after PBT was observed in most patients, even with palliative intent in our study. Also, CA19-9 was declined regardless of administration of chemotherapy, and CA19-9 rose in some patients with chemotherapy. These results suggested local control with PBT is effective 
for control of disease progression. Meanwhile, MST was significantly longer in the patients with maintenance chemotherapy. Therefore, the role of chemotherapy also important with patients who received PBT.

A tumor's macroscopic subtype is important for determining the optimal surgical procedure because each of the 3 types of ICC has a distinct pathological extension pattern. Intrahepatic recurrence is frequent in MF-type tumors, infiltration along the bile duct is frequent in PItype tumors, and lymph node metastases are uncommon in patients with IG-type tumors. The postoperative prognosis of patients with these 3 subtypes are also dissimilar, the MSTs of patients with IG-, MF-, and PI-type tumors are reportedly $17-55$ months $[29,30], 18-50$ months [29-32], and 10-15 months [29, 30], respectively. Although the patients in our cohort had unresectable ICC, the MSTs for those with IG-, MF-, and PItype tumors were 61,31 , and 9.0 months, respectively, which are comparable to those in patients who undergo surgery though our patient's number with PI- and IGtype were small. Moreover, our contouring procedure during dose calculation was the same among patients with all 3 subtypes; however, it may be preferable to contour the target regions while taking into account tumor extension characteristics, which differ among these subtypes.

\section{Conclusion}

Our study was limited in that it was retrospective and included a small number of patients; nevertheless, our data suggested that PBT was safe and effective for patients with unresectable ICC, therefore, we consider that curative PBT for ICC is encouraged, though the definitive criteria has not been established yet. Curative-intent treatment and the administration of maintenance chemotherapy were significant predictors of improved survival; furthermore, the macroscopic tumor type also appears to be an important prognostic factor.

\section{Acknowledgements}

This work was supported by Grant-in-Aid from the Ministry of Education, Science, Sports and Culture of Japan (15H04901, 19H03596), and also supported by Japan Agency for Medical Research and Development, AMED (27251501).

\section{Authors' contributions}

SS drafted initial manuscript, TO conceptualized and designed the study, YO drafted manuscript and analyzed data, NF was doctor in proton therapy, $\mathrm{KF}, \mathrm{KI}$ and $\mathrm{NH}$ were a doctor who specializes in liver of digestive organs and participated in general care, $\mathrm{HN}, \mathrm{KM}$ and $\mathrm{KO}$ helped to make planning, MM participated in coordination and revised the article, $\mathrm{TN}$ and $\mathrm{HI}$ were doctor in proton therapy and participated in coordination and helped to draft the manuscript, HS conceptualized and designed the study, and critically reviewed the manuscript. All authors read and approved the final manuscript.

\section{Funding}

This work did not receive any specific funding.

\section{Availability of data and materials}

The datasets supporting the conclusions of this article are included within the article.

\section{Ethics approval and consent to participate}

All study participants provided informed consent, and we obtained general consent to the research in written form from the participant.

This study was conducted in accordance with the ethical standards defined in the Declaration of Helsinki and was approved by the ethics committee of the University of Tsukuba.(T-CReDO, H30-188).

\section{Consent for publication}

We obtained consent for publication in written form from the participant.

\section{Competing interests}

We have no competing interests.

\section{Author details}

'Department of Radiation Oncology and Proton Medical Research Center, Faculty of Medicine, University of Tsukuba, 1-1-1, Tennodai, Tsukuba, Ibaraki 305-8575, Japan. 'Department of Gastroenterology, Faculty of Medicine, University of Tsukuba, Tsukuba, Ibaraki, Japan.

Received: 18 September 2019 Accepted: 19 December 2019

Published online: 27 December 2019

\section{References}

1. Ustundag Y, Bayraktar Y. Cholangiocarcinoma: a compact review of the literature. World J Gastroenterol. 2008;14(42):6458-66.

2. Ohkawa A, Mizumoto M, Ishikawa H, Abei M, Fukuda K, Hashimoto T, Sakae T, Tsuboi K, Okumura T, Sakurai H. Proton beam therapy for unresectable intrahepatic cholangiocarcinoma. J Gastroenterol Hepatol. 2015;30(5):957-63.

3. Hong TS, Wo JY, Yeap BY, Ben-Josef E, McDonnell El, Blaszkowsky LS, Kwak EL, Allen JN, Clark JW, Goyal L, et al. Multi-institutional phase II study of high-dose Hypofractionated proton beam therapy in patients with localized, Unresectable hepatocellular carcinoma and intrahepatic Cholangiocarcinoma. J Clin Oncol. 2016;34(5):460-8.

4. Nakayama H, Sugahara S, Fukuda K, Abei M, Shoda J, Sakurai H, Tsuboi K, Matsuzaki Y, Tokuuye K. Proton beam therapy for hepatocellular carcinoma located adjacent to the alimentary tract. Int J Radiat Oncol Biol Phys. 2011; 80(4):992-5

5. Hata M, Tokuuye K, Sugahara S, Kagei K, Igaki H, Hashimoto T, Ohara K, Matsuzaki Y, Tanaka N, Akine Y. Proton beam therapy for hepatocellular carcinoma with portal vein tumor thrombus. Cancer. 2005;104(4):794-801.

6. Fukumitsu N, Sugahara S, Nakayama H, Fukuda K, Mizumoto M, Abei M, Shoda J, Thono E, Tsuboi K, Tokuuye K. A prospective study of hypofractionated proton beam therapy for patients with hepatocellular carcinoma. Int J Radiat Oncol Biol Phys. 2009;74(3):831-6.

7. Fukumitsu N, Okumura T, Takizawa D, Numajiri H, Ohnishi K, Mizumoto M, Aihara T, Ishikawa H, Tsuboi K, Sakurai H. Proton beam therapy for liver metastases from gastric cancer. J Radiat Res. 2017:58(3):357-62.

8. Fukumitsu N, Okumura T, Takizawa D, Makishima H, Numajiri H, Murofushi K,

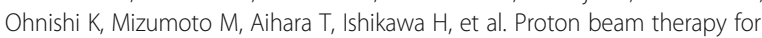
metastatic liver tumors. Radiother Oncol. 2015;117(2):322-7.

9. Liver Cancer Study Group of J. Primary liver cancer in Japan. Clinicopathologic features and results of surgical treatment. Ann Surg. 1990; 211(3):277-87.

10. Hirohashi $K$, Uenishi $T$, Kubo $S$, Yamamoto $T$, Tanaka $H$, Shuto $T$, Yamasaki O, Horii K, Kinoshita $\mathrm{H}$. Histologic bile duct invasion by a mass-forming intrahepatic cholangiocarcinoma. J Hepato-Biliary-Pancreat Surg. 2002;9(2):233-6.

11. Yamamoto M, Takasaki K, Yoshikawa T. Lymph node metastasis in intrahepatic cholangiocarcinoma. Jpn J Clin Oncol. 1999;29(3):147-50.

12. Tsuji T, Hiraoka T, Kanemitsu K, Takamori H, Tanabe D, Tashiro S. Lymphatic spreading pattern of intrahepatic cholangiocarcinoma. Surgery. 2001;129(4):401-7.

13. Tsunashima Y, Sakae T, Shioyama Y, Kagei K, Terunuma T, Nohtomi A, Akine Y. Correlation between the respiratory waveform measured using a respiratory sensor and 3D tumor motion in gated radiotherapy. Int J Radiat Oncol Biol Phys. 2004;60(3):951-8. 
14. Paganetti H, Niemierko A, Ancukiewicz M, Gerweck LE, Goitein M, Loeffler JS, Suit HD. Relative biological effectiveness (RBE) values for proton beam therapy. Int J Radiat Oncol Biol Phys. 2002;53(2):407-21.

15. Mizumoto M, Okumura T, Hashimoto T, Fukuda K, Oshiro Y, Fukumitsu N, Abei M, Kawaguchi A, Hayashi Y, Ohkawa A, et al. Evaluation of liver function after proton beam therapy for hepatocellular carcinoma. Int J Radiat Oncol Biol Phys. 2012;82(3):e529-35.

16. Common Terminology Criteria for Adverse Events (CTCAE) v4.0 [http://evs.nci. nih.gov/ftp1/CTCAE/CTCAE_4.03_2010-06-14_QuickReference_8.5x11.pdf].

17. Park J, Kim MH, Kim KP, Park Do H, Moon SH, Song TJ, Eum J, Lee SS, Seo DW, Lee SK. Natural history and prognostic factors of advanced Cholangiocarcinoma without surgery, chemotherapy, or radiotherapy: a large-scale observational study. Gut Liver. 2009;3(4):298-305.

18. Valle J, Wasan H, Palmer DH, Cunningham D, Anthoney A, Maraveyas A, Madhusudan S, Iveson T, Hughes S, Pereira SP, et al. Cisplatin plus gemcitabine versus gemcitabine for biliary tract cancer. N Engl J Med. 2010; 362(14):1273-81.

19. Riechelmann RP, Townsley CA, Chin SN, Pond GR, Knox JJ. Expanded phase II trial of gemcitabine and capecitabine for advanced biliary cancer. Cancer. 2007;110(6):1307-12

20. Andre T, Reyes-Vidal JM, Fartoux L, Ross P, Leslie M, Rosmorduc O, Clemens MR, Louvet C, Perez N, Mehmud F, et al. Gemcitabine and oxaliplatin in advanced biliary tract carcinoma: a phase II study. Br J Cancer. 2008;99(6):862-7.

21. Sasaki T, Isayama H, Nakai Y, Ito Y, Kogure H, Togawa O, Toda N, Yasuda I, Hasebe O, Maetani I, et al. Multicenter, phase II study of gemcitabine and S1 combination chemotherapy in patients with advanced biliary tract cancer. Cancer Chemother Pharmacol. 2010;65(6):1101-7.

22. Akahoshi K, Ban D, Kuboki R, Oba A, Ono H, Mitsunori Y, Kudo A, Tanaka S, Tanabe M. Orotate phosphoribosyltransferase as a predictor of benefit from S-1 adjuvant chemotherapy for cholangiocarcinoma patients. J Gastroenterol Hepatol. 2019;34(6):1108-15.

23. Foo ML, Gunderson LL, Bender CE, Buskirk SJ. External radiation therapy and transcatheter iridium in the treatment of extrahepatic bile duct carcinoma. Int J Radiat Oncol Biol Phys. 1997;39(4):929-35.

24. Tse RV, Hawkins M, Lockwood G, Kim JJ, Cummings B, Knox J, Sherman M, Dawson LA. Phase I study of individualized stereotactic body radiotherapy for hepatocellular carcinoma and intrahepatic cholangiocarcinoma. J Clin Oncol. 2008;26(4):657-64.

25. Tao R, Krishnan S, Bhosale PR, Javle MM, Aloia TA, Shroff RT, Kaseb AO, Bishop AJ, Swanick CW, Koay EJ, et al. Ablative radiotherapy doses Lead to a substantial prolongation of survival in patients with inoperable intrahepatic Cholangiocarcinoma: a retrospective dose response analysis. J Clin Oncol. 2016;34(3):219-26.

26. Klein J, Dawson LA. Hepatocellular carcinoma radiation therapy: review of evidence and future opportunities. Int J Radiat Oncol Biol Phys. 2013;87(1):22-32.

27. Sugahara S, Oshiro Y, Nakayama H, Fukuda K, Mizumoto M, Abei M, Shoda J, Matsuzaki Y, Thono E, Tokita M, et al. Proton beam therapy for large hepatocellular carcinoma. Int J Radiat Oncol Biol Phys. 2010;76(2):460-6.

28. Makita C, Nakamura T, Takada A, Takayama K, Suzuki M, Ishikawa Y, Azami Y, Kato T, Tsukiyama I, Kikuchi Y, et al. Clinical outcomes and toxicity of proton beam therapy for advanced cholangiocarcinoma. Radiat Oncol. 2014;9:26.

29. Guglielmi A, Ruzzenente A, Campagnaro T, Pachera S, Valdegamberi A, Nicoli P, Cappellani A, Malfermoni G, lacono C. Intrahepatic cholangiocarcinoma: prognostic factors after surgical resection. World J Surg. 2009;33(6):1247-54.

30. Paik KY, Jung JC, Heo JS, Choi SH, Choi DW, Kim YI. What prognostic factors are important for resected intrahepatic cholangiocarcinoma? J Gastroenterol Hepatol. 2008;23(5):766-70.

31. Okabayashi T, Yamamoto J, Kosuge T, Shimada K, Yamasaki S, Takayama T, Makuuchi M. A new staging system for mass-forming intrahepatic cholangiocarcinoma: analysis of preoperative and postoperative variables. Cancer. 2001;92(9):2374-83

32. Suzuki S, Sakaguchi T, Yokoi Y, Okamoto K, Kurachi K, Tsuchiya Y, Okumura T, Konno H, Baba S, Nakamura S. Clinicopathological prognostic factors and impact of surgical treatment of mass-forming intrahepatic cholangiocarcinoma. World J Surg. 2002;26(6):687-93.

\section{Publisher's Note}

Springer Nature remains neutral with regard to jurisdictional claims in published maps and institutional affiliations.

Ready to submit your research? Choose BMC and benefit from:

- fast, convenient online submission

- thorough peer review by experienced researchers in your field

- rapid publication on acceptance

- support for research data, including large and complex data types

- gold Open Access which fosters wider collaboration and increased citations

- maximum visibility for your research: over $100 \mathrm{M}$ website views per year

At BMC, research is always in progress.

Learn more biomedcentral.com/submissions 